\title{
Analysis to determine the average life of the residential building
}

\author{
Wang Cui-ping \\ Xi 'an Shaanxi China Xi'an University of Architecture and Technology email:498386430@qq.com
}

Keywords: Residential building ; life ; Weibull ; regression analysis

Abstract: short-lived building received more and more attention . With the assumed distribution function method to measure the life of residential buildings, with the frequency of things occured in $n$ trials to estimate the probability of something happening, make maximum use of fewer lifetime data , and then regression analysis to determine the life of the residential building meet the Weibull distribution, and determined related parameters, finally using a small group of residential life data in the 1980s calculated the average life of residential building in this area is 45.6 years . Providing an effective method to calculate the average service life of residential construction. Finally through analysis the influence factors of building life, the strategies which can prolong the service life of the building are put forward.

\section{Introduction}

The construction industry plays an important role in China's economic growth, and residential construction is closely related to everyone, especially after residential commercialization, it stimulates investment and domestic demand, injecting a new force to economic growth. With the advance of urbanization, the phenomenon of existing residential buildings which are not reach designed life are removed is appear. In November 2010, the China youth daily social survey center investigate the 31 provinces (cities, districts) including 11824 people, according to the survey $83.3 \%$ of people think that there are "short-lived architecture" [1]. The former deputy minister of national construction $\mathrm{Mr}$. LiuZhifeng in 2010 in the "China-Japan one hundred residential construction peak BBS" pointed out: "because of the housing production pattern of our country, combined with the planning, design, construction, maintenance, management, and other reasons, the service life of the urban residential only 30 years or $\mathrm{so}^{[2]}$. Residential construction has not reached its design service life has been demolished caused great waste, this phenomenon is far away from we build a resource-conserving and environment friendly society, and conflict with the principle of sustainable development strategy, we have reason to believe that extend the service life of buildings is one of the biggest savings.

How long is the service life of the building? Japanese scholar in 1986 to tens of thousands have been demolished residential building of statistical analysis, concluded that the Japanese residential average life is 38.2 years, and our country Taiwan scholars had started building demolition case investigation during 1981 to 2001 in Taiwan, it is concluded that Taiwan's housing demolition duration was 23.21 years on average, As a sample to calculate the average life of residential buildings in Taiwan area obtained for 35 to 40 years .Research on the average life of the residential building in mainland China starts late, LuoQianrong ${ }^{[3.4]}$ using the method of mathematical statistics to study literatures about building life, which can be divided into macro, medium and micro three levels, and found out the research focus and the blind spot. The factors affect the service life of buildings were divided into background and direct factors and put forward extend the life of the building strategy system framework. ChenJian ${ }^{[5]}$ interpretation of the connotation of the service life of buildings, and puts forward the whole life cycle of building evaluation framework. LiRuili ${ }^{[6]}$ according to the structure, basis on damage mechanics, damage parameter as the core, established quantitatively residual life prediction formula. Through reading a lot of building life research materials, found that most study focused on the qualitative analysis and how to prolong life, few of studys can based on the fact and measure the service life. Though some researches using the method of statistical investigation of calculate the average life, but this method requires large amount of sample datas, but guarantee reliable 
of these datas are not easy, in addition the samples obtained have the limitations of area, not typical. On the basis of predecessors' research this article assumed distribution function to calculate the service life of the residential buildings, this method is more operable than the housing distribution function determined by a large number of investigation about the age of residential buildings . and the parameters of the distribution function can revised by the accumulation of actual survey data, the result of prediction is more reliable.

\title{
Connotation and Implications of Residential Life
}

\author{
the connotation of residential life
}

Residential life refers to the total elapsed time from built to dismantle. Residential life with rich connotations, residential as a project entity provide living space for people, although housing form has been changed, but the true nature of this function is not changed. The entity weather-beaten serious wear and tear, because of this reason makes component damage step by step, finally can no longer meet the living function and be dismantled, namely material life is over. Second, due to the economic development and population growth or the change of life demand, makes the original housing can not meet modern residence requirements .As the 1970s and 1980s, tube-shaped apartment is no longer applicable to contemporary life. The residential structure is still can meet the purpose of continue to use, but the function can not meet the requirements can't escape from rebuilding or demolition of fate, so that the function of life to an end and the service life is near the end. In addition, housing as a basic part of the region, its existence state will affect the overall image of the region and at the same time area overall planning and development may also affect whether existing buildings can continue ; Housing as a commodity circulation in the market, has the property of commodity, and will be affected by the market rules, residential life become the reference index of the investment. Because of the above residential properties, it can be summed up as three areas : residential substance life, functional life and socio-economic life. In this article the research of residential life, refers to the residential building from building to the dismantling, did not sort them out according to the cause of the demolition, that is not specific to distinguish the material life, the function of the residence life and social and economic life.

Factors that affect the service life of the residential buildings

Through reading the literature, in order to better analysis of the various factors affecting the service life of buildings, influence factors can be divided into two categories: the external environment factors and their own factors. Their own factors mainly refers to quality defects or design can't meet basic living function, the external environment factors are those in addition to its own factors. Such as in pursuit of a higher economic efficiency, In order to improve the image of the city, Improve more functions, etc. Mainly includes: economic factors, population and family structure, urban planning and government decision-making factors, land value and ownership factors. The dominant factors are social and economic factors, Their own factors are not the main factors.

\section{Residential Average Service Life Calculation Model}

On the basis of literature specific process of hypothesis test, using regression relationship to infer, less actual data on residential building life, with fewer points do return is less than a large number of data points . To make full use of the data, this paper propose the frequency of things occured in $n$ trials to estimate the probability of something happening.

weibull distribution

Weibull distribution is a kind of common life distribution model, the model widely used, its characteristics of probability distribution function is as follows: 
Distribution function : $\mathrm{F}(\mathrm{t})=1-\mathrm{e}^{-\left(\frac{\mathrm{t}}{\eta}\right)^{\mathrm{m}}} \quad$ Density function: $\mathrm{f}(\mathrm{t})=\frac{m}{\eta}\left(\frac{t}{\eta}\right)^{m-1} e^{-\left(\frac{t}{\eta}\right)}$

Mathematical expectation: $\mathrm{E}(\mathrm{T})=\eta \cdot \Gamma\left(1+\frac{1}{m}\right) \quad$ The variance: $\mathrm{D}(\mathrm{T})=\eta^{2}\left[\Gamma\left(1+\frac{2}{m}\right)-\Gamma^{2}\left(1+\frac{1}{m}\right)\right]$ distribution fitting test and parameter estimation

Weibull model was originally used on the life of the electronic product testing, to introduce into the building life must first to test whether building life obey weibull distribution, and then calculate the unknown parameters, then to estimate the average service life. Assuming that the residential life obeys weibull distribution

$$
\begin{aligned}
& \text { Because } F(t)=1-e^{-\left(\frac{t}{\eta}\right)^{m}} \quad \text { Be linearized: } e^{-\left(\frac{t}{\eta}\right)^{m}}=1-F(t) \\
& \text { Logarithmic : }-\left(\frac{t}{\eta}\right)^{m}=\ln (1-\mathrm{F}(\mathrm{t})), \quad \text { Logarithmic again: } \operatorname{mln}\left(\frac{\mathrm{t}}{\eta}\right)=\ln (-\ln (1-\mathrm{F}(\mathrm{t}))
\end{aligned}
$$

make $y=\ln \left(-\ln (1-F(t)), x=\operatorname{lnt}\right.$, Into the linear model $: y=m \operatorname{lnt}-m \ln \eta$, so $y=m x-m \ln ^{\eta}$

We consider using the frequency of residential life which is less than or equal to $t$ in the statistical to estimate its probability. like $\mathrm{F}(1)=\mathrm{P}(\mathrm{T} \leq 1)=\mathrm{i}_{1}, \mathrm{~F}(2)=\mathrm{P}(\mathrm{T} \leq 2)=\mathrm{i}_{2} \ldots \mathrm{F}(\mathrm{n})=\mathrm{P}(\mathrm{T} \leq \mathrm{n})=\mathrm{i}_{\mathrm{n}}$, we can use $\left(1, \mathrm{i}_{1}\right)$, $\left(2, i_{2}\right) \ldots\left(n, i_{n}\right)$ to regression analysis. Call the modeling and evaluation function of the linear regression model-"regress": =regress $(\mathrm{y}, \mathrm{x}$,$) . Find out the coefficient \mathrm{r}^{2}, \mathrm{p}, \mathrm{m}, \mathrm{r}^{2}$ is the bigger, the better, $\mathrm{p}$ is the smaller the better, $r^{2}$ is closer to 1 shows better correlation, the smaller $p$ value the higher acceptable degree, through the program code of function to find the expectation and variance.

\section{Case Analysis}

Using the survey data about service life of the existing 30 house which was built in the 1980s, 23 houses still exist, the life of another 7 houses are 12,13,15,20,21,25,26years, can assume that the house was built in 1980, statistics as in 2014.so

$$
\mathrm{F}(1)=\mathrm{P}(\mathrm{T} \leq 1)=0 \ldots \mathrm{F}(12)=\mathrm{P}(\mathrm{T} \leq 12)=\frac{1}{30} \ldots \mathrm{F}(13)=\mathrm{P}(\mathrm{T} \leq 13)=\frac{2}{30} \ldots \quad \mathrm{F}(34)=\mathrm{P}(\mathrm{T} \leq 34)=\frac{1}{30}
$$

We can write as $(1,0)$ L $(12,1 / 30),(13,2 / 30)$ L $(15,3 / 30)$ L $(20,4 / 30),(21,5 / 30)$ ᄂ $(25,6 / 30)$, $(26,7 / 30),(34,7 / 30)$ to do regression analysis. The Weibull distribution function turned into a linear model $y=\operatorname{mlnt}-\mathrm{mln}^{\eta}$, call regress function returns the coefficient of determination, $F$ statistic value, the estimator of $\mathrm{P}$ and ${ }^{2}$, And building life Weibull distribution fitting and figure chart the values and the parameters as Fig1 and Table1.

According to this article writingcomputer programs that residential life conform to the weibull distribution under the significant level of 0.05. And the 95\% confidence interval for the shape parameter is $[1.7354,2.3810]$. Size parameters, $95 \%$ confidence interval is $[-9.0731,-7.1525]$. Then calculated $\mathrm{m}=2.0582 \eta=51.509, \mathrm{E}(\mathrm{T})=45.6296, \operatorname{var}(\mathrm{T})=540.3050$.

\section{Conclusions}

Due to less information about residential life, in order to take full advantage of less data, using 


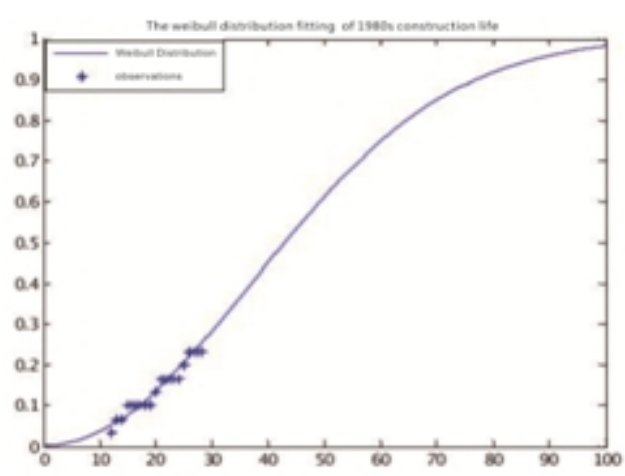

Fig1

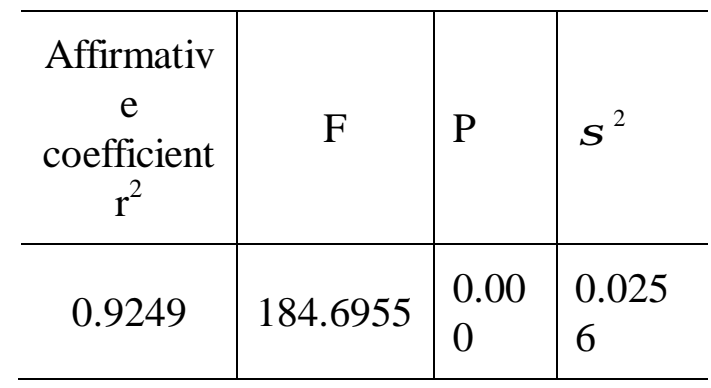

Table1

frequency estimate the probability to do linear regression. According to the existing data by calling the regress function of determination coefficient of 0.9249 has been very close to 1 , we have reason to accept hypothesis that residential life meet weibull distribution. At the same time obtained the shape parameter and size parameters through writing the program code get the mathematical expectation of the Weibull distribution, by using the existing residential data we can calculate the average life is 45.6296 year. Along with the accumulation of data related to the service life of the residential buildings, the parameters of the distribution function can be constantly revised, the result of prediction is more reliable.

Grasping the main factors standing on the height of the urban development and update, focus on the building's external environment factors, pay attention to the concept and system innovation. First, the government department should improve the appraisal of the cadre management system, to strict control the construction project during his tenure. Strengthen the urban and rural planning act, with the law governing the implementation of urban planning, real play to the readjustment of planning, pay attention to the role of urban planning space, improve the forward-looking and scientific of architectural planning. Eliminating regional segmentation, fragmented in the planning and construction. Strengthen the penalties for illegal enterprises. Secondly, the construction industry and scientific research colleges and universities should strengthen the study of both the construction and reform, improve the design standard and quality, improve the quality of construction, advocate the CSI residential promotion, pay attention to the maintenance of buildings, etc. Again, as building users, should strengthen people's consciousness, increase the consciousness of regular maintenance construction, cautious to decide the fate of the building.

\section{References}

[1] Gui-wen liu. 2012.The service life of demolished buildings research - based on field investigation and analysis of chongqing city, Urban development research, 19(10):109-112.

[2]Liu zhi-feng. 2010.China and Japan in one hundred residential construction peak BBS. Hangzhou: China academy of building one hundred,.

[3]Luo Qianrong. 2011. Our country related theory and its development trend of building life [J]. Journal of cooperation in economy and technology, 12: $18-20$

[4]Luo Qianrong. 2011. The factors affecting the service life of building research. Chongqing: chongqing university.

[5]Chen jian. 2007.Under the sustainable development of building life research. Tianjin: tianjin university. 
[6]Li Ruili. 2007. Modern buildings under the general working environment of the residual life prediction. Journal of building structures, 5 (3) : 66-68. 